\section{Draft Genome Sequence Resources of Three Strains (TOS4, TOS5, and TOS14) of Xylella fastidiosa Infecting Different Host Plants in the Newly Discovered Outbreak in Tuscany, Italy}

\author{
Annalisa Giampetruzzi, ${ }^{1}$ Giusy D'Attoma, ${ }^{2}$ Stefania Zicca, ${ }^{2}$ Raied Abou Kubaa, ${ }^{2}$ Domenico Rizzo, ${ }^{3}$ \\ Donato Boscia, ${ }^{2}$ Pasquale Saldarelli, ${ }^{2}$ and Maria Saponari ${ }^{2, \dagger}$ \\ ${ }^{1}$ Dipartimento di Scienze del Suolo della Pianta e degli Alimenti, Università degli Studi di Bari Aldo Moro, \\ 70126 Bari, Italy \\ ${ }^{2}$ Istituto per la Protezione Sostenibile delle Piante, CNR, 70126 Bari, Italy \\ ${ }^{3}$ Regione Toscana, Servizio Fitosanitario Regionale e di Vigilanza e Controllo Agroforestale, 50121 \\ Firenze, Italy
}

\begin{abstract}
An outbreak of Xylella fastidiosa was discovered in late 2018 in northern Italy affecting several plant species. Multilocus sequence typing analyses detected the presence of strains clustering in X. fastidiosa subsp. multiplex and harboring a hitherto uncharacterized sequence type, ST87. Three cultured strains (TOS4, TOS5, and TOS14) were subjected to high-throughput sequencing and the draft genomes assembled. Phylogenetic analysis conclusively indicated that they belong to the subspecies multiplex. The genetic information generated for these newly discovered strains further supports the evidence that sequence types are associated with the emergence of $X$. fastidiosa in Europe, posing major challenges for predicting the main threatened European and Mediterranean crops and plant species.
\end{abstract}

\section{Genome Announcement}

In December 2018, while carrying out the official annual surveys for Xylella fastidiosa, more than 70 infected plants were identified in a small promontory of the region of Tuscany (northern Italy), resulting in the demarcation of an infected area of approximately 130 ha. The most frequently infected plants were Rhamnus alaternus, followed by Polygala myrtifolia, Spartium junceum, Calicotome spinosa, and Cistus spp. Indeed, infections were also reported on a few plants (from one to three) of Prunus amygdalus, Lavandula spp., and Ficus carica (EUROPHYT n. 718). Although the majority of the infected plants were symptomless, leaf scorching was recorded on $P$. amygdalus, Polygala myrtifolia, and $S$. junceum.

Multilocus sequence typing analyses conducted by two independent research teams indicated that the infections were associated with isolates genetically related to $X$. fastidiosa subsp. multiplex and harboring a novel sequence type (ST) (Marchi et al. 2018), identified as ST87 (Saponari et al. 2019) and closely related to ST6, ST7, and ST81, previously reported in Europe. This finding further confirms the large genetic diversity detected within the subspecies multiplex in the European outbreaks, accounting for the highest number of reported STs (EFSA Panel on Plant Health 2018).

In this report, we describe the draft genome sequences of $X$. fastidiosa strains TOS4, TOS5, and TOS14, cultured from symptomatic plants of Prunus dulcis, Polygala myrtifolia and $S$. junceum L., respectively. Genomic DNA of strains TOS4, TOS5, and TOS14 were extracted from pure cultures grown on periwinkle wilt-GelRite (Hill and Purcell 1995) medium, using a

${ }^{\dagger}$ Corresponding author: M. Saponari; maria.saponari@ipsp.cnr.it

The author(s) declare no conflict of interest.

Accepted for publication 1 May 2019.

\section{Funding}

This work was funded by Project XF-ACTORS (Xylella fastidiosa active containment through a multidisciplinaryoriented research strategy; grant ID number 727987) from the European Union's Horizon 2020 Food research and innovation programme.

\section{Keywords}

bacteriology, multiplex, ST87,

Xylella fastidiosa 
Table 1. Comparative analyses of the growth rate, cell-surface attachment, and cell-to-cell aggregation yielded for Xylella fastidiosa subsp. multiplex strains ESVL, TOS4, TOS5, and TOS14

\begin{tabular}{lccc} 
Strains & $\begin{array}{c}\text { Growth rate } \\
\left(\mathbf{O D}_{\mathbf{6 0 0}} \text { day }^{-1}\right)(\text { mean } \pm \mathbf{S D})^{\mathbf{x}}\end{array}$ & $\begin{array}{c}\text { Cell-surface attachment } \\
\left(\mathbf{O D}_{\mathbf{6 0 0}}\right)(\text { mean } \pm \mathbf{S D})^{\mathrm{y}}\end{array}$ & $\begin{array}{c}\text { Cell-to-cell aggregation } \\
\left(\mathbf{O D}_{\mathbf{6 0 0}} \mathbf{m i n}^{-1}\right)\left(\mathbf{m e a n}^{\mathbf{1}} \mathbf{S D}\right)^{\mathbf{z}}\end{array}$ \\
ESVL & $0.67 \pm 0.21 \mathrm{a}$ & $0.15 \pm 0.02 \mathrm{a}$ & $0.001 \pm 0.00 \mathrm{a}$ \\
TOS4 & $0.49 \pm 0.13 \mathrm{a}$ & $0.18 \pm 0.01 \mathrm{a}$ & $0.229 \pm 0.02 \mathrm{~b}$ \\
TOS5 & $0.62 \pm 0.12 \mathrm{a}$ & $0.14 \pm 0.02 \mathrm{a}$ & $0.320 \pm 0.08 \mathrm{~b}$ \\
TOS14 & $0.54 \pm 0.15 \mathrm{a}$ & $0.15 \pm 0.03 \mathrm{a}$ & $0.236 \pm 0.03 \mathrm{~b}$ \\
\hline
\end{tabular}

w Data, analyzed by IBM SPSS Statistics for Windows (IBM Corp. 2015), are the average of three independent experiments. SD = standard deviation. Comparisons among numeric data sets were conducted using the one-way analysis of variance followed by posthoc Tukey's test. Statistical significance was accepted for $P$ values $<0.05$ ( $\alpha$ level). Different lowercase letters indicate statistically significant differences between groups.

x Growth rates were calculated from the growth curve at the exponential growth phase. Growth curves were generated by measuring optical density values at $600 \mathrm{~nm}\left(\mathrm{OD}_{600}\right)$ each day for 8 days.

y Cell-surface attachment was evaluated by using crystal violet assay at the end of the growth-curve experiment.

$z$ Cell-to-cell aggregation, calculated as settling rate, was measured by suspending the bacteria in phosphate-buffered saline and measuring $\mathrm{OD}_{600}$ values at 30 -s intervals for $10 \mathrm{~min}$.

commercial DNA purification kit (DNeasy Plant Mini kit; Qiagen). The whole-genome sequencing libraries were paired-end sequenced with a NovaSeq 6000 Illumina platform.

Illumina sequencing yielded a total of 27,293,263, 25,569,349, and 26,843,928 $2 \times 150$-bp (with an average quality per read score of 36) paired reads for TOS4, TOS5, and TOS14, respectively. De novo genome assembly was done using SPAdes v3.9.0 using multiple kmer $(31,51,61,71,81,91,101$, and 127) and trying to reduce number of mismatches and short indels (-careful option). The presence of contigs annotated as a plasmid sequence was searched running the plasmidSPAdes tool (Antipov et al. 2016; Bankevich et al. 2012) and by PCR amplification with specific primers. The final assemblies of the bacterial chromosomes resulted in 77 contigs for the strain TOS4, 72 contigs for TOS5, and 80 contigs for TOS14, with an equal GC content of $51.7 \%$ (N50 was 134,638 for TOS4, 131,357 for TOS5, and 131,346 for TOS14). The nucleotide coverage of the chromosomal genome was $1,637 \times$ for TOS4, 1,534x for TOS5, and 1,610x for TOS14. Pairwise comparisons of the draft genome assemblies showed an average nucleotide identity higher than $99.99 \%$ (Lee et al. 2016).

For all three strains, functional annotation by submission to the NCBI Prokaryotic Genome Automatic Annotation Pipeline resulted in the identification of 6 ribosomal RNA genes (two operons), 50 tRNA loci, and 3 noncoding RNAs, whereas the protein-encoding genes were 2,272 in strain TOS4, 2,270 in strain TOS5, and 2,277 in strain TOS14. No circular contigs were detected by in silico analysis and no amplifications were obtained when primers targeting plasmid sequences previously described for $X$. fastidiosa were used in PCR reactions.

In vitro studies were performed to assess the growth rate, biofilm formation, and bacterial aggregation of these three strains in comparison with a selected EU strain of $X$. fastidiosa subsp. multiplex, the ST6 strain ESVL, previously characterized in Spain (Giampetruzzi et al. 2019). Growth curves were generated by measuring cell turbidity for 10 days in periwinkle wilt (PW) liquid media, adhesion to the surface was measured by using crystal violet assay (Cruz et al. 2012), and cell-to-cell aggregation was determined by measuring optical density at $600 \mathrm{~nm}$ in phosphate-buffered saline cell suspensions over $10 \mathrm{~min}$ (Kandel et al. 2017). The evaluation of the growth rates, cell-surface attachment, and cell-to-cell aggregation confirmed that all three strains had the same behavior and, when the results were compared with those recovered for the strain ESVL, statistically significant differences were recovered only for the cell-to-cell aggregation test, with values higher for the three strains from Tuscany (Table 1). This difference was consistent with the observation that, when cultured on different solid media, these three strains tend to form large aggregated and clearly distinguishable colonies, whereas the ESVL strain grows in very small contiguous colonies.

The genome sequences produced for the strains TOS4, TOS5, and TOS14 isolated in Italy and harboring the newly reported ST87 further contribute to extend the genomic data available for the European strains of $X$. fastidiosa subsp. multiplex. These data, coupled with different sources of information such as the monitoring data, can help to gather more insights into the dynamics of this reemerging plant pathogen by elucidating putative pathways and events of introduction in Europe and by understanding the main drivers of the infections.

Nucleotide sequence accession numbers. The genome sequences of $X$. fastidiosa strains TOS4, TOS5, and TOS14 have been deposited in GenBank under the accession numbers SMTH00000000, SMTI00000000, and SMTJ00000000, respectively. 


\section{Acknowledgments}

We thank the "Rete di Laboratori Pubblici SELGE-Regione Puglia (cod. 14)" and the datacenter ReCaS of University of Bari Aldo Moro for the equipment used for the bioinformatic analysis.

\section{Literature Cited}

Antipov, D., Hartwick, N., Shen, M., Raiko, M., Lapidus, A., and Pevzner, P. 2016. plasmidSPAdes: Assembling plasmids from whole genome sequencing data. Bioinformatics 32:3380-3387.

Bankevich, A., Nurk, S., Antipov, D., Gurevich, A. A., Dvorkin, M., Kulikov, A. S., Lesin, V. M., Nikolenko, S. I., Pham, S., Prjibelski, A. D., Pyshkin, A. V., Sirotkin, A. V., Vyahhi, N., Tesler, G., Alekseyev, M. A., and Pevzner, P. A. 2012. SPAdes: A new genome assembly algorithm and its applications to single-cell sequencing. J. Comput. Biol. 19:455-477.

Cruz, L. F., Cobine, P. A., and De La Fuente, L. 2012. Calcium increases Xylella fastidiosa surface attachment, biofilm formation, and twitching motility. Appl. Environ. Microbiol. 78:1321-1331.

EFSA Panel on Plant Health (EFSA PLH Panel), Jeger, M., Caffier, D., Candresse, T., Chatzivassiliou, E., Dehnen-Schmutz, K., Gilioli, G., Grégoire, J.-C., Miret, J. A. J., MacLeod, A., Navarro, M. N., Niere, B., Parnell, S., Potting, R., Rafoss, T., Rossi, V., Urek, G., Van Bruggen, A., Van der Werf, W., West, J., Winter, S., Almeida, R., Bosco, D., Jacques, M.-A., Landa, B., Purcell, A., Saponari, M., Czwienczek, E., Delbianco, A., Stancanelli, G., and Bragard, C. 2018. Updated pest categorisation of Xylella fastidiosa. EFSA J. 16: Article e05357.

Giampetruzzi, A., Velasco-Amo, M. P., Marco-Noales, E., Montes-Borrego, M., RománÉcija, M., Navarro, I., Monterde, A., Barbé, S., Almeida, R. P. P., Saldarelli, P., Saponari, M., Montilon, V., Savino, V. N., Boscia, D., and Landa, B. B. 2019. Draft genome resources of two strains ("ESVL" and "IVIA5901") of Xylella fastidiosa associated with almond leaf scorch disease in Alicante, Spain. Phytopathology 109: 219-221.

Hill, B. L., and Purcell, A. H. 1995. Acquisition and retention of Xylella fastidiosa by an efficient vector, Graphocephala atropunctata. Phytopathology 85:209-212.

IBM Corp. 2015. IBM SPSS Statistics for Windows, Version 23.0. IBM Corp., Armonk, NY, U.S.A.

Kandel, P. P., Almeida, R. P., Cobine, P. A., and De La Fuente, L. 2017. Natural competence rates are variable among Xylella fastidiosa strains and homologous recombination occurs in vitro between subspecies fastidiosa and multiplex. Mol. Plant-Microbe Interact. 30:589-600.

Lee, I., Kim, Y. O., Park, S. C., and Chun, J. 2016. OrthoANI: An improved algorithm and software for calculating average nucleotide identity. Int. J. Syst. Evol. Microbiol. 66: 1100-1103.

Marchi, G., Rizzo, D., Ranaldi, F., Ghelardini, L., Ricciolini, M., Scarpelli, I., Drosera, L., Goti, E., Capretti, P., and Surico, G. 2018. First detection of Xylella fastidiosa subsp. multiplex DNA in Tuscany (Italy). Phytopathol. Mediterr. 57:363-364.

Saponari, M., D’Attoma, G., Abou Kubaa, R., Loconsole, G., Altamura, G., Zicca, S., Rizzo, D., and Boscia, D. 2019. A new variant of Xylella fastidiosa subspecies multiplex detected in different host plants in the recently emerged outbreak in the region of Tuscany, Italy. Eur. J. Plant Pathol. doi.org/10.1007/s10658-01901736-9 